\title{
Informe Epidemiológico do SUS
}

A informação em saúde tem sido posta em questão no país nos últimos anos. Foram realizados diversos encontros em torno do tema, ou nos quais a questão esteve presente (Abrasco, 1990a, 1992; Seminário Nacional de Vigilância Epidemiológica, 1992), e produzidos estudos acadêmicos e documentos (Moraes, 1991; Abrasco, 1990b) analisando os sistemas de informações existentes, suas estruturas, coberturas e adequações ao Sistema Único de Saúde.

A perspectiva de reordenar e compatibilizar os diversos sistemas existentes é a tônica da maioria dos documentos institucionais e das conclusões dos eventos recentemente realizados. Ou seja, superar a distorção atual de bancos de dados isolados e compartimentalizados por programas e agravos. Acompanhando estas propostas aparece a perspectiva de redefinir o sistema de vigilância epidemiológica do país, tomando como referência os elementos conceituais e doutrinários da Reforma Sanitária (Paim \& Teixeira, 1992).

O próprio surgimento do Centro Nacional de Epidemiologia (Cenepi) pode ser saudado como resultado deste amplo movimento crítico e propositivo que se faz a Epidemiologia no país.

Desde julho passado temos mais um motivo de regozijo e satisfação nesta área: o surgimento desta excelente coleção que é o Informe Epidemiológico do SUS. Ele aparece com o objetivo de "organizar e divulgar, de forma mais ampla, algumas informações epidemiológicas que vinham sendo acumuladas de forma compartimentalizada em vários órgãos do M inistério da Saúde" (Cherquer \& Teixeira, 1992). O informe é resultado da agregação de programas de controle de diversos órgãos do Ministério antes dispersos, bem como da integração com outros sistemas de informações da Secretaria de Ações Básicas de Saúde (SNAS), Instituto Nacional de Assistência Médica da Previdência Social (Inamps) e do Departamento de Informática do SUS da Fundação Nacional de Saúde (Datasus).

Nos seus cinco números já editados, assumiu um papel insubstituível para todos aqueles que, por lidarem com a saúde, precisam ter à mão informações de qualidade sobre agravos e produção do sistema.
A publicação está organizada sempre com um, dois ou mais artigos de fundo, analisando com mais profundidade um tema relevante da área. Assim, nesta seção já foram abordados temas como a ocorrência do cólera no Brasil; a morbidade psiquiátrica em regiões metropolitanas do país; a polarização epidemiológica; as tendências da mortalidade infantil no Brasil nos anos 80; os acidentes de trabalho e as doenças profissionais; a situação atual e as perspectivas para a doença de Chagas, para a febre tifóide, e para a AIDS no Brasil; as práticas conceptivas entre as mulheres do recôncavo bahiano; a reorganização do sistema nacional de vigilância epidemiológica; o uso das informações sobre mortalidade em São Paulo; notas técnicas sobre anos potenciais de vida perdidos; e o diagrama de ramo e folha.

Além disso, publicou o relatório final do Seminário Nacional de Vigilância Epidemiológica e os resultados condensados do estudo multicêntrico sobre diabetes no Brasil.

Outra grande atração do Informe são as séries sobre doenças infecciosas e parasitárias comparativas entre 1991 e 1992, por unidade federada; as séries históricas (1980-1991) sobre doenças transmissíveis e acidentes por animais peçonhentos; e as séries, mês a mês, sobre causas de internações hospitalares e óbitos, por unidade federada.

Sua tiragem é de 15.000 exemplares e sua distribuição é feita para inúmeras organizações públicas e privadas de todo o país. Resta-nos solicitar ao Ministério da Saúde que dê todo o apoio possível para a manutenção da publicação, que se constitui, sem dúvida, numa das mais importantes contribuições surgidas nos últimos anos nos campos da epidemiologia e da informação em saúde.

\section{REFERÊNCIAS BIBLIOGRÁFICAS}

ABRASCO (Associação Brasileira de Pós-Graduação em Saúde Coletiva), 1990a. A nais do I Congresso Brasileiro de Epidemiologia. Campinas: Abrasco.

, 1990b. Plano Diretor para o Desenvolvimento da Epidemiologia no Brasil. Rio de Janeiro: Abrasco. 
, 1992. A nais do II Congresso Brasileiro de Epidemiologia. Belo Horizonte: Abrasco.

CHERQUER, P. \& TEIXEIRA, M. G., 1992. Introdução. Informe Epidemiológico do SUS, 1: 5.

MORAES, I. H. S., 1991. Sistemas de Informações em Saúde: Reflexões sobre sua Prática Fragmentada. Tese de Mestrado, Rio de Janeiro: Escola Nacional de Saúde Pública.

PAIM, J. S. \& TEIXEIRA, M. G. L. C., 1992. Reorganização do Sistema de Vigilância Epidemiológica na Perspectiva do SUS. Informe Epidemiológico do SUS, 5: 27-57.
SEMINÁRIO NACIONAL DE VIGILÂNCIA EPIDEMIOLÓGICA, 1992. Relatório Final. Informe Epidemiológico do SUS, 5: 3-24.

Paulo M. Buss Vice-Presidência de Ensino e Informação Fundação Oswaldo Cruz Avenida Brasil, 4365 21040-360, Rio de Janeiro, RJ, Brasil 